\title{
A ASSIMETRIA FEDERATIVA NO AFASTAMENTO DE CHEFES DO EXECUTIVO: UMA ANÁLISE DO CASO WILSON WITZEL
}

Paulo César Rebouças Torquato Antônio Gustavo Gonçalves Sombra

O sistema federativo caracteriza-se como um modelo jurídico-político baseado na união de entes que configuram um Estado nacional. No Brasil, a Constituição Federal de 1988 designou uma série de entes federados, quais sejam: a União, os Estados, os Municípios e o Distrito Federal. Nesse sentido, as incongruências advindas do modelo brasileiro expõem alguns problemas jurídicos e políticos, como pode ser percebido com o recente caso envolvendo o Governador do Estado do Rio de Janeiro, Wilson Witzel (PSC), que foi afastado do cargo diante de acusações de corrupção por decisão monocrática do ministro Benedito Gonçalves, do Superior Tribunal de Justiça (STJ). As peculiaridades advindas desse caso se coadunam com a assimetria federativa brasileira, que promove distinções significativas em relação ao afastamento de chefes do Executivo nacional, mediante a assimetria presente por determinações constitucionais, bem como a atuação dos tribunais superiores na centralização de poderes da União em face dos Estados e Municípios.

O sistema federalista é a definição da prerrogativa de repartição e compartilhamento de poderes. $\mathrm{O}$ primeiro projeto federalista foi idealizado na Assembleia Constituinte que elaborou a Constituição Política dos Estados Unidos da América, de 1787 (LIZIERO, 2018, p. 13). No pacto federativo brasileiro, apesar de ser um modelo instituído desde a proclamação da República, em 1889, a dinâmica federalista nacional baseiase na centralização de competências da União em detrimento dos estados e municípios.

Durante os diferentes períodos históricos e políticos do país, tal centralização mostrou-se como uma característica central do federalismo que aqui se propunha. A Assembleia Nacional Constituinte de 1987/1988 teve o desafio e a oportunidade de redesenhar o modelo federativo brasileiro, se debruçando diante das desigualdades e problemas intrínsecos ao país. No entanto, embora os trabalhos das comissões e subcomissões responsáveis por restabelecer uma nova forma federal para o país tivessem um relevante desejo de descentralizar a federação brasileira, com a promulgação da Constituição Federal, em 5 de outubro de 1988, o resultado do texto constitucional revelou um federalismo altamente centralizador e simétrico (LIZIERO, 2018, p. 98). Por esse motivo, a pergunta-problema que norteará esta resenha baseia-se em: como a simetria federativa brasileira contribui para tratamentos distintos entre chefes do Executivo nos entes subnacionais?

Desse modo, o objetivo (geral) do presente trabalho diz respeito à análise da simetria federalista constitucional a partir dos problemas jurídico-políticos da centralização de competências e o afastamento dos chefes dos Executivos estaduais como consequência; já os objetivos (específicos) são: i) analisar o 
procedimento e os efeitos da decisão do Superior Tribunal de Justiça (STJ), por ocasião do afastamento do Governador do Estado do Rio de Janeiro, Wilson Witzel (PSC); ii) compreender como as decisões do Supremo Tribunal Federal (STF), em sede de controle de constitucionalidade, potencializam a centralização de autonomias e poderes na União; e iii) investigar caminhos para a reformulação do pacto federativo nacional que perpassem as regras de afastamento dos chefes do Executivo.

Apresentados os objetivos, expõe-se a metodologia. O presente trabalho contou com um estudo lógico-dedutivo e crítico a partir da análise legal e jurisprudencial do sistema federativo nacional. Em termos documentais, foram utilizadas obras que esclarecessem e dissessem respeito ao fenômeno federalista e à experiência brasileira no assunto. Por fim, serão analisadas decisões dos tribunais superiores que condizem com a dinâmica centralizadora e simétrica do pacto federativo nacional, bem como do caso de Wilson Witzel.

A simetria do modelo federalista diz respeito à ausência de hierarquia dos entes subnacionais que compõem o Estado, ao tratamento isonômico na representação política federal e na distribuição de competências destes. Nesse sentido, a Constituição Federal, art. 18, caput, estabelece que os entes que compõem a República brasileira são autônomos, isto é, independentes entre si. Entretanto, essa simetria, além de inviabilizar a atuação dos estados nas matérias que lhes são especificamente pertinentes, demonstra a diferenciação nos tratamentos político-jurídicos entre os entes federados, porquanto os submete ao controle da União em matérias especificamente sensíveis aos seus interesses que costumeiramente não são contempladas pela representação federal em Brasília. Essa inviabilização ocorre por determinação constitucional. O rol de possibilidades legislativas competentes privativamente à União, que é estabelecido no art. 22 da Constituição, representa a assimetria e centralização de direito que excede de competências à União, a despeito das possibilidades residuais deixadas aos Estados, Municípios e Distrito Federal.

Para Raul Machado Horta (1985, p. 18), a divisão de competências na federação é uma característica muito relevante, ao passo que quando há centralização de um ente em face dos demais não existe um sistema federativo verdadeiro e eficaz. Seguindo o pensamento de Hans Kelsen, Horta identifica o federalismo simétrico como uma estrutura normativa que se distribui em planos distintos, sendo o Estado federal o detentor do ordenamento jurídico principal do qual serão concebidos os ordenamentos estaduais, o que difere do modelo brasileiro, uma vez que o próprio ordenamento central, ou seja, a Constituição Federal, não concebeu uma distribuição minimamente equânime de competências legislativas (1988, p. 85).

As formas de centralização do Estado federal brasileiro estão dispostas, também, no processo constitucional dos estados-membros. A autonomia dada pela Constituição Federal não capacitou aos estados a prerrogativa de legislarem baseados em suas necessidades e interesses diante de suas constituições. Nesse sentido, o processo de impugnação das normas constitucionais dos estados ocorre, em sua maioria, em sede de controle de constitucionalidade, realizado pelo Supremo Tribunal Federal (STF), que interpela as normas valorando suas razões baseadas no princípio da simetria constitucional.

Desse modo, a simetria da federação brasileira expõe inúmeras controvérsias no que diz respeito aos processos de impedimento dos chefes do Executivo nos diferentes entes subnacionais. Com as Ações Diretas 
de Inconstitucionalidade (ADIns) nº 4.798 e 4.764, o STF declarou incompatíveis com a Constituição Federal as normas das constituições do Estado do Piauí e do Acre que estabeleciam que o processo de afastamento dos governadores dos respectivos estados, por intermédio do Superior Tribunal de Justiça, só poderia ocorrer após aprovado pelas Assembleias Legislativas. Na decisão, o STF salienta que, embora o STJ não precise de aval das Assembleias, os governadores não poderão ser afastados automaticamente após aceitação da denúncia do Ministério Público Federal (MPF) por parte da Justiça.

As ações que buscaram reconhecer a inconstitucionalidade das normas estaduais referendaram a centralização por parte do STF. A autonomia constitucional dos estados é irrisória à medida que, se valendo do chamado princípio da simetria, as decisões vindas do Supremo acabam por delimitar a atuação legislativa dos estados, culminando em constituições que replicam o texto de 88. Estas ADIns representam a diferenciação do processo jurídico-político de impedimento entre os entes federados, o que se chamaria de simetria de fato. No recente caso que envolve o Governador do Estado do Rio de Janeiro, Wilson Witzel (PSC), o problema expõe um precedente perigoso no que concerne ao cargo de Governador do estado no país.

Ao julgar inconstitucionais as normas estaduais que versam sobre a autonomia das Assembleias Legislativas em permitir o afastamento de seus governadores, o Supremo Tribunal Federal atua como agente dessa centralização que deixa para as constituições estaduais apenas a possibilidade de legislar sobre normas de caráter amplo. É válido lembrar que a Suprema Corte do país anuiu que, no âmbito do Senado Federal, os senadores só poderiam ser afastados de suas funções quando o plenário da Casa assim permitisse, o que demonstra uma diferenciação relevante quando se trata das instituições ligadas à União e aquelas ligadas aos Estados. No caso Witzel, os efeitos dessas decisões do Supremo se delinearam na interpretação do STJ que culminou no seu afastamento. O caso será analisado a seguir.

No dia 12 de agosto de 2020, a Procuradoria-Geral da República solicitou ao Superior Tribunal de Justiça o afastamento e a prisão do Governador do Rio de Janeiro, Wilson Witzel (PSC), por ocasião de acordos de delação premiada firmados entre o Ministério Público Federal e o ex-secretário de Saúde do estado, Edmar Santos. No decorrer de seis dias, portanto, no dia 18 de agosto, o ministro do Superior Tribunal de Justiça, Benedito Gonçalves, anuiu parcialmente em decisão monocrática, com o pedido do Ministério Público. Ocorre que o processo apresenta uma série de vícios, haja vista que a decisão do Min. Benedito Gonçalves que acatou o pedido de afastamento no dia 18, ocorreu sem que sequer a defesa do Governador fosse ouvida, e o próprio Witzel fosse chamado para prestar esclarecimentos diante das acusações imputadas pelo ex-secretário do Governo do Estado.

A análise da decisão monocrática foi feita no dia 2 de setembro pela Corte Especial do STJ, quando a Turma a referendou. O detalhe desse processo é que a defesa do governador afastado só foi chamada a se manifestar no dia da apreciação da decisão do Min. Gonçalves, quando o governador já estava afastado há mais de 10 dias. Wilson Witzel foi afastado do cargo mediante denúncia dos crimes de corrupção passiva, lavagem de dinheiro e formação de quadrilha. A denúncia afirma que Witzel, em razão do seu cargo, constituiu uma organização criminosa que movimentou, apenas no contexto da pandemia da COVID-19, , mais de meio 
milhão de reais em propina paga por empresários do ramo da saúde ao escritório de advocacia da primeiradama do Rio de Janeiro, Helena Witzel.

O óbice de toda controvérsia do caso, além de demonstrar a simetria federativa no trato dos chefes do Executivo, expõe um déficit democrático, uma vez que o afastamento de um governador de Estado eleito, através de uma decisão monocrática, demonstra um grave precedente jurídico e político à medida que se põe em risco a instabilidade dos executivos estaduais em todo o país. Pelos efeitos da decisão do STJ, os acordos de delação premiada ganham margem significativa como meios acusatórios em persecuções penais, o que poderia culminar, a qualquer governador do país, a sujeição ao afastamento do cargo, baseado em delações sem conteúdo probatório relevante e por uma decisão monocrática.

Os vícios processuais dessa decisão ocorrem à medida que a instrução processual ainda não havia começado quando o governador foi afastado, pois sequer a defesa e/ou Witzel foram intimados a se manifestar diante das acusações e da decisão do min. Gonçalves. Outro problema da decisão parte de uma ordem jurídico-política: a delação premiada de Edmar Santos, até a data de seu depoimento - que é considerada a maior prova contra o governador -, não apresentou meios probatórios mínimos que referendassem suas versões dos fatos, o que inviabilizaria a utilização de sua delação como principal meio acusatório na denúncia. Ainda, a decisão do min. Gonçalves foi contrária ao entendimento do STF no que concerne à impossibilidade de afastamento dos governadores automaticamente após a recepção da denúncia por parte da Justiça. A assimetria no presente caso é reafirmada pela própria diferença procedimental a que se submetem os chefes do Executivo nacionalmente.

Nesse sentido, a Constituição Federal, art. 86, caput, estabelece que o Presidente da República somente será afastado do seu cargo por aceitação de, no mínimo, dois terços de votos na Câmara dos Deputados com prosseguimento no Senado Federal. Desse modo, no ambiente constitucional brasileiro, seria impensável presumir o afastamento do Presidente a partir de decisões monocráticas que ocorressem sem um amplo direito à defesa e ao contraditório. O princípio da simetria que o Supremo Tribunal Federal se vale para restringir a autonomia dos estados não é utilizado para que os governadores passem pelo mesmo procedimento quando se trata do afastamento de suas funções, bem como representa um processo cada vez mais constante de centralidade político-institucional da União em detrimento dos demais entes federados.

O regime federativo brasileiro é considerado o maior do mundo em virtude do reconhecimento constitucional de entes além da União e dos Estados. A forma de descentralização das competências destes entes é baseada em atribuições residuais, quando não muito abrangentes e de pouca eficácia. Dessa forma, o modelo de centralização firmado na União contribui para uma série de dificuldades e distinções do modelo constitucional federativo brasileiro, que culmina em crises sucessivas diante da institucionalidade dos mais altos cargos do país.

Embora a Constituição vede a hierarquia entre tais entes, a diferenciação jurídica e política é relevante e presente. O caso de Wilson Witzel (PSC) representa essas diferenças. Para além do julgamento moral e político a que se submete os agentes públicos em cargos eletivos, o afastamento do Governador, por 
decisão monocrática e sem o direito prévio a defesa, demonstra serias irregularidades nos processos nacionais de afastamento dos chefes dos Executivos, bem como maculam entendimentos jurisprudenciais das cortes superiores.

O redesenho do pacto federativo brasileiro, portanto, faz-se mister e urgente. Apesar de ser cláusula pétrea constitucional, não há vedação para a reformulação dos padrões institucionais federativos. O caminho deverá ser percorrido através da descentralização de autonomias dos entes federados e análise da eficácia acerca do reconhecimento dos municípios como parte destes entes. A descentralização poderá ser a solução para inúmeras dificuldades nacionais decorrentes do excesso de competências centradas na União, em detrimento de competências abstratas e residuais a cabo dos Estados, Municípios e Distrito Federal.

Tendo como base o pacto federativo nacional, regedor do federalismo no Brasil, assim como todas as incoerências que vêm se apresentando com a tratativa dos chefes dos entes federativos estaduais, é possível inferir que, atualmente, o federalismo brasileiro encontra incongruências. O caso de Wilson Witzel é apenas um dos exemplos onde a autonomia dos entes federativos estaduais é cessada para garantir a supremacia da União, mesmo que não seja sua competência para tratar do mérito de questões jurídicas e políticas nos mandatos dos Governadores.

Os recentes acontecimentos envolvendo o caso Witzel denunciam as desigualdades inerentes ao pacto federativo nacional determinado na Constituição de 88. Para além dos problemas simétricos advindos destes fatos, o Estado Democrático de Direito é violado quando o devido processo legal de agentes eleitos é negligenciado e quando a escolha política de uma parcela da população é vedada por uma decisão monocrática. As dificuldades nacionais apresentam-se inúmeras com o atual regime de centralização, haja vista o processo contínuo de ampliação de poderes praticados pelas instituições pertencentes à União, bem como a limitação funcional a que se submete os demais entes, hoje incapazes de decidir sobre seus interesses legítimos em âmbito local.

\section{REFERÊNCIAS BIBLIOGRÁFICAS}

BRASIL. Constituição da República Federativa do Brasil. Secretaria de Editoração e Publicações do Senado Federal. Brasília, 2015.

BRASIL. Superior Tribunal de Justiça. Cautelar Inominada Criminal no 36 - DF. Relator: Ministro Benedito Gonçalves. Brasília, 2020. Disponível em https://politica.estadao.com.br/blogs/fausto-macedo/wpcontent/uploads/sites/41/2020/08/1-convertido-1_280820201439.pdf. Acesso em: 04 de setembro de 2020.

BRASIL. Supremo Tribunal Federal. Arguição de Descumprimento de Preceito Fundamental $n^{\circ} 4.764$. Re 1 a tor: Ministro Luís Roberto Barroso. Dis poníve 1 e m http://www.stf.jus.br/portal/cms/verNoticiaDetalhe.asp?idConteudo=342480. Acesso em: 16 de outubro de 2020. 
BRASIL. Supremo Tribunal Federal. Arguição de Descumprimento de Preceito Fundamental no 4.798. Relator: Min. Celso de Mello. Brasília, DF: Supremo Tribunal Federal, 2020. Disponível em: http://www.stf.jus.br/arquivo/cms/noticiaNoticiaStf/anexo/ADI4798votorelator.pdf. Acesso em: 16 out. 2020.

HORTA, Raul Machado. Organização Constitucional do Federalismo. Revista de informação legislativa, v. 22, n. 87, p. 5-22, jul./set. $1988 \mid$ Revista da faculdade de direito da Universidade Federal de Minas Gerais, v. 30, n. 28/29, p. 9-32 de 1985/1986. Disponível em <https://www2.senado.leg.br/bdsf/item/id/181618>. Acesso em: 13 de outubro de 2020.

LIZIERO, Leonam Baesso da Silva. Estado Federal no Brasil: o federalismo na Constituinte de 1987/1988 e a descentralização pela assimetria. Ed. Modara. Florianópolis 2018. Disponível em < https://emaiseditora.com.br/livro/o-estado-federal-no-brasil-o-federalismo-na-constituinte-de-1987-1988-

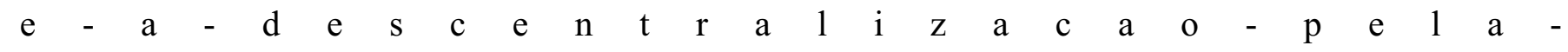
assimetria/\#: :text=Leonam\%20Baesso\%20da\%20Silva\%20Liziero,e $\% 20 \mathrm{a} \% 20$ descentraliza $\% \mathrm{C} 3 \% \mathrm{~A} 7 \%$ C3\%A3o\%20pela\%20assimetria.\&text=O\%20trabalho\%20tem\%20por\%20escopo,de\%20constituinte $\% 2$ 0de\%201987\%2F1988.>Acesso em: 04 de setembro de 2020. 